\title{
Child malnutrition and the Millennium Development Goals: much haste but less speed?
}

\author{
Raphael S Oruamabo
}

\begin{abstract}
Correspondence to
Professor Raphael $S$

Oruamabo, P. O. Box 126,

Uniport Post Office,

Shopping Complex, Choba,

Port Harcourt, Nigeria;

raphael_oruamabo@hotmail.

com
\end{abstract}

Received 30 May 2014

Revised 14 October 2014

Accepted 15 October 2014

\begin{abstract}
The Millennium Development Goals (MDGs) provide a framework for measuring the progress of nations. Several of these goals relate to child malnutrition, which remains an important contributor to child morbidity and mortality, accounting for approximately $45 \%$ of child deaths globally. A high proportion of undernourished children still live in Africa and parts of Asia, and the uneven rate of reduction in the prevalence of various types of child malnutrition among different income groups worldwide is worrying. Attempts to reduce child malnutrition should therefore begin from the grassroots by improving primary healthcare services in developing countries with particular focus on basic requirements. Adequate nutrition should be provided from birth, through infancy, preschool and early childhood to adolescence. The overall strategy should be one of careful and meticulous planning involving all development sectors with an emphasis on a bottom-up approach within a stable and disciplined polity; the MDGs will be only be useful if they are seen not as narrow objectives with unidirectional interventions but as multifaceted and co-ordinated. The setting of deadlines, whether 2015 or 2035, should not be emphasised so as to avoid hasty decision making. The top priority should be the implementation of the essential social services of basic education, primary healthcare, nutrition, reproductive health care, water and sanitation in partnership with the developed economies.
\end{abstract}

\section{INTRODUCTION}

The Millennium Development Goals (MDGs) provide a framework for measuring the progress of nations, ${ }^{1}$ and several of these goals address-directly and indirectly_child malnutrition, which remains an important contributor to child morbidity and mortality. Approximately $45 \%$ of child deaths globally may be caused by under-nutrition which leaves children susceptible to infectious disease. $^{2}$ Therefore, there is a dynamic relationship between child nutrition and most of the MDGs, especially MDGs $2,3,5,6$ and $7 .^{3}$

MDG1 to eradicate extreme poverty and hunger has three subtargets (IA, IB and IC) and a total of nine indicators: three, four and two for subtargets IA, IB and IC, respectively. ${ }^{4}$ The dynamic relationship among various societal development sectors is outlined in figure $1 .^{5}$ As shown, malnutrition, injury and infections are the result of several related influences acting on the individual, classified here into intermediate and distal, ${ }^{5}$ with the distal factors exerting a strong influences on the intermediate factors. Consequently, children living near the type of rubbish depicted in figure 2 are at risk of a vicious cycle of infection, malnutrition and more infection.

Therefore, child malnutrition is strongly dependent on several societal development sectors and hence attempts to reduce it require a multidimensional approach. It is within this framework that this topic is discussed.

\section{DEFINITION OF TERMS AND TRENDS IN CHILD MALNUTRITION FROM 1990 TO 2015}

Malnutrition is the failure of the body to get the appropriate amounts of nutrients to maintain healthy tissues and organ function. Iron deficiency is common and affects about $18.1 \%$ and $20.2 \%$ of children globally and in Africa, respectively. ${ }^{2}$ Worldwide, under-nutrition, including vitamin A and zinc deficiencies, accounts for approximately 3.1 million child deaths annually in low- and middle-income countries. Three anthropometric indices are used to define child nutritional status: weight-for-height (wasting), height-for-age (stunting) and weight-for-age (underweight). For any one of these indices, malnutrition is defined as a $\mathrm{z}$ score below $-2.0 .^{2}$ In addition, the WHO reference standards define two categories of severity: severe acute malnutrition (SAM) and moderate acute malnutrition (MAM). SAM is defined as a weight-for-height below $-3.0 \mathrm{z}$ scores below the median in children 6-59 months of age, and/or a mid-upper arm circumference (MUAC) $<115 \mathrm{~mm}$ and/or the presence of bilateral pitting oedema, while MAM is defined as a weight-for-height between -3.0 and $-2.0 \mathrm{z}$ scores below the median, or MUAC between $115 \mathrm{~mm}$ and $125 \mathrm{~mm}$ and no oedema. ${ }^{6}$ Malnutrition occurring in childhood can have serious health implications later in life.

In developing countries worldwide, the proportion of children aged under-five with stunting decreased between 1990 and 2011 to approximately $26 \%$, but remained high in Africa $36 \%$ in 2011) and Asia (27\% in 2011). Similarly, the proportion of underweight under-fives dropped globally to $16 \%$ between 1990 and 2011 . $^{7}$ However, anthropometric status worsened in sub-Saharan Africa until the late 1990s but improved thereafter. In 2011, 314 million children below 5 years of age were mildly, moderately or severely stunted, and 258 million were mildly, moderately or severely underweight. $^{8}$

At the other end of the spectrum, overweight malnutrition is beginning to be a public health problem, with a global estimate of 43 million (7\%) overweight children under 5 years of age in 2011, a 54\% increase from an estimated 28 million in $1990 .^{2}$

This article focuses on the first three categories of stunting, underweight and wasting. 


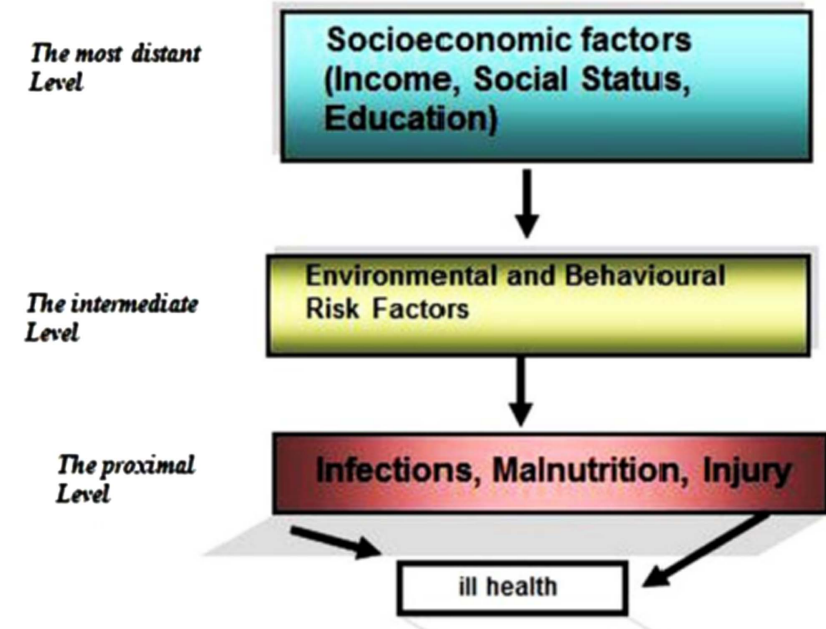

Figure 1 Malnutrition and illness in general are the result of factors such as social and environmental influences impacting on the individual. Adapted from Mosley and Chen. ${ }^{5}$

\section{CHILD MALNUTRITION, THE MDGS AND ASPECTS OF SOCIAL EPIDEMIOLOGY}

MDG1 aims to eradicate extreme poverty and hunger by 2015 , by halving (i) the number of people living on less than US $\$ 1.25$ a day and (ii) the number people suffering from hunger. It also aims to achieve full and productive employment and decent work for all, including women and young people. Of the nine indicators, the author considers the most important to be the two addressing a reduction in the prevalence of underweight children and the proportion of the population consuming less than the minimum required dietary energy.

Available evidence indicates that the world will not achieve MDG1. Of even more significance are the uneven rates of achievement in different parts of the globe. For instance, the largest decline in the prevalence of malnutrition has been in East Asia, especially in China, while substantial improvements have been made in Latin America and the Caribbean. However, less progress was seen in South Asia, where the prevalence of underweight remains very high, while sub-Saharan Africa saw little or no change over the period 1990-2011. ${ }^{8}$ Another

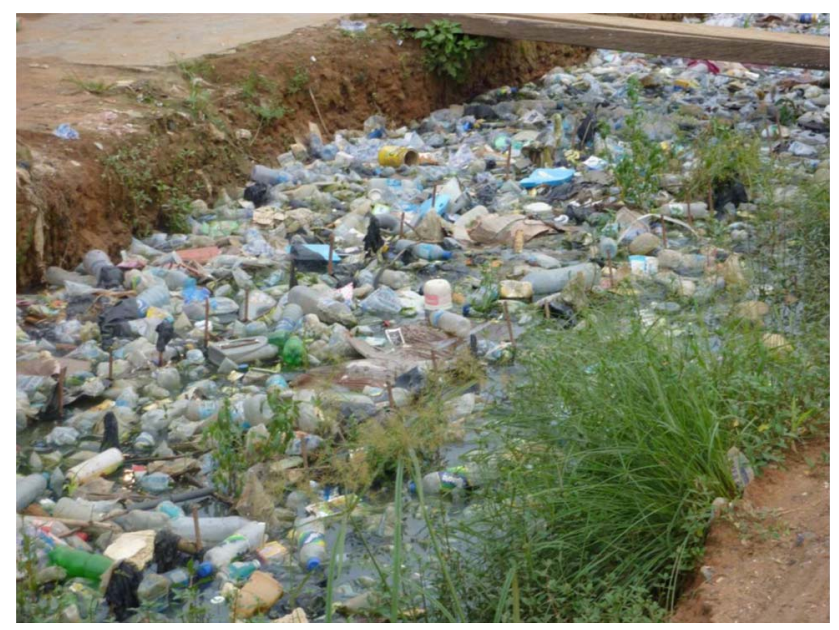

Figure 2 An unhealthy environment: a blocked drain filled with refuse very close to a residential area. worrying aspect is the urban/rural disparity in the rate of reduction in most countries. Thus, children in rural communities are more malnourished than their urban counterparts. In some countries, the percentage of rural children who are underweight is over $50 \%$ higher than for urban children. ${ }^{9}$

Thus, rates of reduction in the prevalence of the various categories of child malnutrition vary among different income groups worldwide, and the projections of WHO, UNICEF and the World Bank indicate the 2015 target will not be met with the present rates of progress. ${ }^{8}$

Basic education, particularly of girls, is very important for achieving the MDGs. However, female education still lags behind that of males in some African countries. For instance, youth literacy rates for 2007-2011 for males and females, respectively, were $76 \%$ and $67 \%$ in sub-Saharan Africa, $80 \%$ and $72 \%$ in East and Southern Africa, and $73 \%$ and $61 \%$ in West and Central Africa, compared to a world average of $92 \%$ and $87 \% .{ }^{10}$ Maternal mortality rates are still relatively high in African countries; the adjusted 2010 figures for sub-Saharan Africa, Eastern and Southern Africa, West and Central Africa and the world average are 500, 410, 570 and 210 per 100000 live births, respectively. ${ }^{11}$ The picture was equally bleak a decade ago regarding the general HIV situation in Africa, ${ }^{12}$ but there is now some light at the end of the tunnel. Currently, more than 7 million people in Africa are accessing HIV treatment, and there were 33\% fewer AIDS-related deaths in Africa in 2011 than in 2005, ranging from 25\% less in Chad to $71 \%$ less in Botswana. Improvements in anti-retroviral therapy are a cause for optimism since HIV has slowed down advances in various areas, particularly education. ${ }^{13}$

\section{BRIDGING THE GAPS}

Attempts to bridge the gaps between the MDGs and the current position should give priority to the vital role of adequate nutrition in the first 5 years of life, particularly the critical first 3 years of rapid brain development. Unhealthy children cannot be properly educated, while uneducated children cannot be fully healthy. Well-nourished children have a better chance of surviving, of learning easily, and of growing into healthy adults. Therefore, it is vital to ensure adequate nutrition from the neonatal period, through infancy, preschool and early childhood into adolescence.

\section{Breastfeeding}

Breast-milk is important for infant survival; it has anti-infective properties and provides adequate nutrition for the neonate. WHO and UNICEF recommend that mothers commence breastfeeding within $1 \mathrm{~h}$ of birth, do so exclusively for the first 6 months and continue for at least 2 years while also providing nutritional, safe and age-appropriate solid, semi-solid and soft foods starting in the sixth month. ${ }^{2}{ }^{14}$ Breast-feeding reduces overall neonatal mortality and by extension under-five mortality. $^{2} 15$

However, the study by Cai et al showed that exclusive breastfeeding rates worldwide only increased slightly between 1995 and 2010, showing only a modest increase from 33\% to $39 \%$ in developing countries, with the biggest improvement seen in West and Central Africa. They concluded that breast-feeding was still not widespread in the developing world, with only a small increase globally. Therefore, they recommended more investment in child nutrition programmes worldwide. ${ }^{16}$ The author agrees with this suggestion, but with the addition that primary healthcare (PHC) services should be improved in developing countries with particular focus at the household level and 
on providing optimal support for nursing mothers in the home and in the work place through legislation. ${ }^{17}$ The provision of adequate nutrition should be seamless and continuous from birth, through infancy, preschool and early childhood to adolescence. Adequate nutrition during the pre-school years should be ensured through adherence to the UNICEF recommendation that countries should develop comprehensive infant and child feeding programs at national and community level. This should include early detection by screening and prompt treatment of SAM in both emergency and non-emergency settings with ready-to-use therapeutic foods and adequate treatment of complications, while supplementary feeding should be used in the management of MAM. ${ }^{18}$ During the school years, adequate nutrition should be guaranteed by implementing school health programmes (SHPs) especially in developing countries, as suggested previously. ${ }^{19}$

\section{The SHP as a model for multisectoral collaboration}

The SHP in Nigeria covers all aspects of school management that contribute to the understanding, maintenance and improvement of the school population. ${ }^{20}$ The most important factors for preventing child malnutrition are a healthy school environment and school feeding programs. The former ensures the health and safety of students and other members of the school community, while the latter encourages healthy eating patterns, which are essential if students are to achieve their academic potential, full physical and mental growth, and lifelong health and well-being. Furthermore, schools operate within religious and local communities and interact with government institutions, allowing regular communication and overall improvement in the management of schools. This model, if scaled up and replicated at government level, should guarantee multisectoral collaboration, the emphasis being on the bottom-up approach, particularly in developing countries.

\section{Provision of potable water and environmental sanitation}

A good SHP provides a clean environment and potable water, and also inculcates in students awareness of a healthy lifestyle, which encourages health-seeking behaviour later in life. The WHO/UNICEF Joint Monitoring Programme (JMP) reports on progress in improving sanitation and water supplies, ${ }^{21}$ as shown in table 1.

There was a demonstrable improvement globally in the provision of potable water between 1990 and 2010. However, there are regional disparities in the level of improvement. For instance, while $90 \%$ or more of the population in Latin America and the Caribbean, Northern Africa and large parts of Asia have access to improved water supply sources, this figure is only $61 \%$ in sub-Saharan Africa. In the developing world overall, $86 \%$ have access to improved water supply sources, but in the least developed countries only $63 \%$ have access. There are similar disparities within countries-between the rich and poor and between rural and urban areas. ${ }^{21} 22$

The picture is similar for the use of improved sanitation facilities. Southern Asia and sub-Saharan Africa have low coverage of $41 \%$ and $30 \%$, respectively. The disparities in rural and urban sanitation are even more pronounced than those for improved drinking water supply. Globally, $79 \%$ of the urban population uses an improved sanitation facility, compared to $47 \%$ of the rural population. In rural areas, 1.8 billion people lack access to improved sanitation, representing $72 \%$ of the global total of those without access. ${ }^{22}$

\section{CONCLUDING REMARKS}

Nutritional status reflects deprivation related to living conditions. Thus a child may be malnourished not because their parents are poor, but because of other related reasons. Socioeconomic factors and particularly the educational level of the mother, access to clean water and sanitation, infant feeding practices and freedom from illness, especially diarrhoeal disease, are all important.

The eight MDGs provide a framework by which progress can be assessed. Progress measured at the global, regional and country level indicates the feasibility of the MDGs at that level. In addition, global trends are estimates and not actual values, and the method of data collection may be unreliable and challenge the very concept of the MDGs.

The deadline for the MDGs is 2015 and all, including the least developed nations, are attempting to meet this target. However, given the economic, social and political circumstances of some countries, this goal will not be achieved. Caution is therefore advised regarding premature claims by some leaders, particularly in sub-Saharan Africa, that MDGs have been met.

The overall strategy should be one of careful and meticulous short, medium and long term planning involving all development sectors with an emphasis on a bottom-up approach within a stable and disciplined polity. Progress has to be sustained and implementation rigorously monitored. The setting of deadlines, whether 2015 or 2035 , should be not be emphasised to avoid hasty decisions as the finishing line is not necessarily the same

Table 1 Definition of improved and unimproved water sources and sanitation facilities

\begin{tabular}{|c|c|c|}
\hline & Improved & Unimproved \\
\hline $\begin{array}{l}\text { Use of drinking } \\
\text { water }\end{array}$ & $\begin{array}{l}\text { Piped water into dwelling yard or plot } \\
\text { Public tap or standpipe } \\
\text { Tube well or borehole } \\
\text { Protected spring } \\
\text { Protected dug well } \\
\text { Rain water collection }\end{array}$ & $\begin{array}{l}\text { Unprotected dug well } \\
\text { Unprotected spring } \\
\text { Cart with small tank or drum } \\
\text { Tanker truck } \\
\text { Surface water (river, dam, lake, pond, stream, canal, irrigation channel) } \\
\text { Bottled water (considered to be improved only when the household uses } \\
\text { drinking water from an improved source for cooking and personal hygiene) }\end{array}$ \\
\hline Use of sanitation & $\begin{array}{l}\text { Flush or pour flush to a piped sewer system, septic tank or pit } \\
\text { latrine } \\
\text { Ventilated improved pit } \\
\text { Pit latrine with slab } \\
\text { Composting toilet }\end{array}$ & $\begin{array}{l}\text { Flush or pour-flush to elsewhere (ie, not to piped sewer system, septic tank or pit } \\
\text { latrine) } \\
\text { Pit latrine without slab, or open pit } \\
\text { Bucket } \\
\text { Hanging toilet or hanging latrine } \\
\text { Shared or public facilities of any type }\end{array}$ \\
\hline
\end{tabular}

Adapted from the WHO/UNICEF Joint Monitoring Programme. ${ }^{21}$ 
for all. The most urgent need now is peace as well as good governance with equitable distribution of national and international resources. Sustained development is not possible in the midst of social chaos. ${ }^{23}$ The MDGs will be useful tools only if they are seen as multifaceted and co-ordinated rather than as narrow objectives requiring simple interventions.

The top priority should be implementation of the essential social services of basic education, PHC, nutrition, reproductive health care, water and sanitation in partnership with the developed economies. ${ }^{24}$ It is from this perspective that child nutrition has been discussed, because adequate infant nutrition guarantees optimal child growth, and only when this has been achieved for the majority will governments be able to accelerate sustained economic development. $^{25}$

Acknowledgements The author is grateful to Emeritus Professor Kelsey A Harrison of the Department of Obstetrics and Gynaecology and Professor Alice R Nte of the Department of Child Health, both of the University of Port Harcourt, Nigeria for reading through drafts of the manuscript and making vary useful comments and suggestions.

Competing interests None.

Provenance and peer review Commissioned; externally peer reviewed.

\section{REFERENCES}

1 United Nations. Millennium Declaration. New York: United Nations, 2000.

2 Black RE, Victora CG, Walker SP, et al. Maternal and child under nutrition and overweight in low-income and middle-income countries. Lancet 2013;382:427-51.

3 Gillespie SR, Lawrence $H$. The relationship between nutrition and the Millennium Development Goals: a strategic review of the scope for DFID's influencing role. IFPRI Report. Washington: International Food Policy Research Institute, 2003.

4 United Nations General Assembly. Road map towards the implementation of the United Nations Millennium Declaration. 2001:55-8.

5 Mosley WH, Chen LC. An analytical framework for the study of child survival in developing countries. Bull World Health Organ 2003;81:140-5.

6 WHO Multicentre Growth Reference Group. WHO Child Growth Standards. Length/ height-for-age, weight-for-age, weight-for-length, weight-for-height and body mass index-for-age. Methods and Development. www.who.int/childgrowth/standards. technical_report/en/index.html
7 Levels and Trends in Child Malnutrition. United Nations Children's Fund, World Health Organization, the World Bank. UNICEF-WHO-World Bank Joint Child Malnutrition Estimates. UNICEF, New York: WHO, Geneva: The World Bank, Washington, DC, 2012.

8 Stevens GA, Finucane MM, Paciorek CJ, et al. Trends in mild, moderate, and severe stunting and underweight, and progress towards MDG 1 in 141 developing countries: a systematic analysis of population representative data. Lancet 2012;380:824-38.

9 Garcia V. Children malnutrition and horizontal inequalities in sub-Saharan Africa: a focus on contrasting domestic trajectories. UNDP Working Paper 2012-019. March 2012.

10 Education, Statistical Tables. State of the World's Children. UNICEF, 2013:117-19.

11 Women. Maternal Mortality Ratios, Statistical Tables. State of the World's Children. UNICEF, 2013:129-31.

12 HIVIAIDS, Statistical Tables. State of the World's Children. UNICEF, 2013:113-15.

13 Update: How Africa turned AIDS around. UNAIDS Report 2013. http://www.unaids. org/en/resources/documents/2014/name,97466, en.asp

14 Butte NF, Lopez-Alarcon MG, Garza C. Nutrient adequacy of exclusive breastfeeding for the term infant during the first six months of life. Geneva, Switzerland: World Health Organization, 2002.

15 Mullany LC, Katz J, Li YM, et al. Breast-feeding patterns, time to initiation, and mortality risk among newborns in southern Nepal. J Nutr 2008;138:599-603.

16 Cai X, Wardlaw T, Brown DW. Global trends in exclusive breast-feeding. Int Breastfeed J 2012;7:1-5.

17 Breast-feeding Support: Close to Mothers. WABA World Breastfeeding Week. 2013. http://www.worldbreastfeedingweek.org

18 Tracking Progress on Child and Maternal Nutrition. A survival and development priority. UNICEF, 2009.

19 Oruamabo RS. Guidelines for severe malnutrition. back to basics. Arch Dis Child 2007;92:193-4.

20 Federal Ministry of Health, Nigeria 2006. Implementation Guidelines on National School Health Programme.

21 Progress on Drinking Water and Sanitation 2012 Update. UNICEF \& WHO. http://www.unicef.org/media/files/JMPreport2012.pdf

22 Health, Statistical Tables. State of the World's Children. UNICEF, 2013:101-3.

23 Horton R. Offline: social chaos - the ignored tragedy in social health. Lancet 2014;383:111.

24 Scaling up Nutrition. A Framework for Action-UNSCN. http://www.unscn.org/.../ Scaling_Up_Nutrition_A_Framework_for_Action.pdf

25 De Onis M, Blossner $\mathrm{M}$, Borghi $\mathrm{E}$, et al. Methodology for estimating regional and global trends of child malnutrition. Int J Epidemiol 2004;33:1260-70. 